\title{
Plasma adiponectin and serum advanced glycated end-products increase and plasma lipid concentrations decrease with increasing duration of type 2 diabetes
}

\author{
A Gottsäter ${ }^{1}$, B Szelag ${ }^{2}$, M Kangro $^{3}$, M Wroblewski $^{2}$ and G Sundkvist ${ }^{4}$ \\ Departments of ${ }^{1}$ Vascular Diseases, ${ }^{2}$ Medicine, ${ }^{3}$ Ophthalmology, ${ }^{4}$ Endocrinology, University of Lund, Malmö University Hospital, Malmö, Sweden \\ (Correspondence should be addressed to A Gottsäter; Email: anders.gottsater@skane.se)
}

\begin{abstract}
Objective: To prospectively follow the concentrations of plasma adiponectin (p-adiponectin) and serum advanced glycation end-products (s-AGE) in relation to plasma lipids and retinopathy over 3 years in type 2 diabetic patients.

Design and methods: P-adiponectin, s-AGE, plasma lipids and diabetic retinopathy were prospectively evaluated in 61 type 2 diabetic patients at baseline and at follow up 3 years later.

Results: Mean p-adiponectin (from $8.84 \pm 5.14$ to $11.05 \pm 6.16 \mu \mathrm{g} / \mathrm{ml} ; P=0.006$ ) and s-AGE (from $637 \pm 242$ to $781 \pm 173 \mathrm{ng} / \mathrm{ml} ; P<0.0001)$ concentrations had increased at follow up. In addition, HbA1c $(7.7 \pm 1.7$ to $7.4 \pm 1.4 \% ; P=0.0045)$ and fasting C-peptide $(1.00 \pm 0.38$ to $0.81 \pm 0.35 \mathrm{nM}$; $P=0.019)$ had decreased and all lipid variables had significantly improved at follow up. P-adiponectin correlated inversely with fasting $C$-peptide $\left(r_{\mathrm{s}}=-0.273 ; P=0.045\right)$ and low-density lipoprotein (LDL)/high-density lipoprotein (HDL) ratio $\left(r_{\mathrm{s}}=-0.362 ; P=0.011\right)$, and directly with plasma HDL cholesterol $\left(r_{\mathrm{s}}=0.381 ; P=0.005\right)$ at follow up. Analysis of variance with adiponectin and s-AGE as dependent variables and fasting $\mathrm{C}$-peptide, plasma HDL and plasma LDL cholesterol as covariates demonstrated that the increase in s-AGE was independent $(P=0.001)$ and the increase in p-adiponectin dependent on covariate changes $(P=0.862)$. There was a slight correlation between s-AGE at baseline versus the degree of retinopathy at follow up $\left(r_{\mathrm{s}}=0.281 ; P=0.0499\right)$.

Conclusion: Both p-adiponectin and s-AGE increased during the 3 years. The increase in p-adiponectin was explained by improvements in insulin sensitivity and dyslipidaemia, whereas the increase in s-AGE was independent of changes in metabolic covariates. s-AGE increase when the duration of type 2 diabetes increases.
\end{abstract}

European Journal of Endocrinology 151 361-366

\section{Introduction}

Adiponectin is an adipocyte-specific bioactive protein secreted from adipose tissue (1). In animal models, adiponectin deficiency results in insulin resistance (2). In healthy individuals, adiponectin is negatively correlated with body mass index (BMI) (3) and plasma triglyceride concentrations $(4,5)$ and positively associated with plasma high-density lipoprotein (HDL) cholesterol concentrations (3-5) and increased insulin sensitivity (6). Among type 2 diabetic patients, cross-sectional studies have shown that low plasma adiponectin (p-adiponectin) concentrations (7) are associated with low plasma HDL cholesterol concentrations (8). There is a need for prospective studies to establish the relationship between plasma adiponectin and lipids among type 2 diabetic patients.

Among diabetic patients, increments of advanced glycation end-products (AGE) (9) have been associated with disturbed lipid metabolism. AGE-modified lowdensity lipoprotein (LDL) impairs the LDL receptormediated clearance mechanism (10), AGE-modified HDL has disturbed function (11) and AGE may directly inhibit the scavenger receptor class B I-mediated reverse cholesterol transport (12). Possibly as a consequence of this, increased serum AGE (s-AGE) concentrations are associated with increased plasma triglycerides and LDL concentrations in children and adolescents with type 1 diabetes (13). Increased serum concentrations of AGE may in addition contribute to the development of vascular complications by inducing endothelial dysfunction (14) and retinopathy $(15,16)$. Although irreversible glycation should be increased by prolonged hyperglycaemic exposure, s-AGE concentrations were not increased in children and adolescents with long durations of type 1 diabetes $(13,17)$. Indeed, s-AGE decreased in a 10-year prospective study of insulin treated, mainly type 1 diabetic 
patients (18). It is now important to prospectively follow the progression of s-AGE in type 2 diabetic patients.

The aim of this study was to prospectively follow the development of p-adiponectin and s-AGE in relation to plasma lipids, plasma C-peptide and retinopathy over 3 years in type 2 diabetic patients.

\section{Subjects and methods}

\section{Subjects}

From a population-based study of the diabetes incidence in Malmö, Sweden, between 1990 and 1992 (19), 61 newly diagnosed patients with type 2 diabetes (all negative for islet antibodies) were investigated with regard to biochemical risk factors 5 years after the diagnosis of diabetes (baseline examination) (20). Their age ranged from 45 to 69 years, with a median value of 59 years. These investigations were repeated 8 years after diagnosis (follow-up examination).

Informed consent was obtained from all subjects. The study was conducted in accordance with the Declaration of Helsinki and approved by the ethics committee of Lund University.

\section{Analytical methods}

BMI was measured as weight (in $\mathrm{kg}$ )/height squared (in $\mathrm{m}^{2}$ ). Blood pressure (BP) was measured in the supine position with a sphygmomanometer in the right upper arm after 10 min rest. P-adiponectin concentrations were measured using a RIA for human adiponectin (Linco Research, St Louis, MO, USA) (4). s-AGE concentrations were measured using an $N$ - $\varepsilon$-carboxymethyl-lysine (CML) ELISA system (Roche Diagnostics, Penzberg, Germany) (18).

\section{Retinopathy}

An experienced ophthalmologist (M Kangro) assessed diabetic retinopathy from fundus photography. The 11 levels of the alternative classification on the Wisconsin scale were used $(21,22)$. Level 10 represents no retinopathy, levels 21-51 nonproliferative diabetic retinopathy (NPDR) of increasing severity, and levels $60+$ all forms of proliferative diabetic retinopathy (PDR), with and without laser treatment. The eye with the more severe level of retinopathy determined the patient's retinopathy level.

\section{Statistical methods}

Differences between groups were evaluated with the Mann-Whitney U test and the $\chi^{2}$ test. Differences over time within groups were evaluated with the Wilcoxon signed-rank test. In analysis of variance with repeated design p-adiponectin and s-AGE were dependent variables, and correlating variables were covariates. Tests were two-tailed and $P$ values $<0.05$ were considered significant. Results are presented as mean \pm S.D. StatView 4.5 (SAS Institute, Cary, NC, USA) was used for the statistical calculations.

\section{Results}

\section{Adiponectin}

There was a significant $(P=0.006)$ increase in mean p-adiponectin from $8.84 \pm 5.14 \mu \mathrm{g} / \mathrm{ml}$ at baseline to $11.05 \pm 6.16 \mu \mathrm{g} / \mathrm{ml}$ at follow up (Table 1). In parallel

Table 1 Treatment, clinical features, p-adiponectin and s-AGE at baseline and 3 years later in 61 type 2 diabetic patients. Means \pm S.D. or $n(\%)$ are shown. P, plasma; Fp-C-peptide, fasting plasma C-peptide.

\begin{tabular}{lcrr}
\hline & Baseline & Follow up & $P$ value \\
\hline Treatment $(n(\%))$ & & & \\
Anti-hypertensive & $20(33)$ & $23(38)$ & 0.5696 \\
Lipid lowering & $2(3)$ & $11(18)$ & 0.0022 \\
Insulin & $3(5)$ & $7(11)$ & 0.1811 \\
Sulphonylurea & $34(56)$ & $38(62)$ & 0.5795 \\
Biguanide & $11(18)$ & $27(44)$ & 0.0028 \\
Clinical features & $6(10)$ & $14(23)$ & 0.0179 \\
Retinopathy $(n(\%))$ & $139 \pm 17 / 87 \pm 10$ & $147 \pm 20 / 89 \pm 9$ & $0.1195 / 0.033$ \\
BP $(\mathrm{mmHg})$ & $29.3 \pm 5.4$ & $28.2 \pm 4.6$ & 0.001 \\
BMI (kg/m $)$ & $1.00 \pm 0.38$ & $0.81 \pm 0.35$ & 0.019 \\
Fp-C-peptide $(\mathrm{nM})$ & $7.68 \pm 1.72$ & $7.38 \pm 1.44$ & 0.0045 \\
HbA1c $(\%)$ & $5.78 \pm 0.95$ & $5.34 \pm 1.04$ & 0.0003 \\
P-cholesterol $(\mathrm{mM})$ & $3.72 \pm 0.81$ & $3.17 \pm 0.76$ & $<0.0001$ \\
P-LDL $(\mathrm{mM})$ & $1.08 \pm 0.26$ & $1.27 \pm 0.36$ & $<0.0001$ \\
P-HDL (mM) & $2.26 \pm 1.63$ & $1.92 \pm 1.10$ & 0.0431 \\
P-triglycerides $(\mathrm{mM})$ & $8.84 \pm 5.14$ & $11.05 \pm 6.16$ & 0.0055 \\
P-adiponectin $(\mu \mathrm{g} / \mathrm{ml})$ & $637 \pm 242$ & $781 \pm 173$ & $<0.0001$ \\
s-AGE $(\mathrm{ng} / \mathrm{ml})$ & & & \\
\hline
\end{tabular}


with this, several variables including BMI indicated improved metabolic control. Table 1 shows that $\mathrm{HbA1c}$, fasting plasma C-peptide and all lipid variables were significantly improved at follow up. There was an increased use of biguanides (baseline 11/61 (18\%) versus follow up 27/61 (44\%); $P=0.0028)$, and lipid-lowering drugs (baseline 2/61 (3\%) versus follow up $11 / 61$ (18\%); $P=0.0022$; Table 1). However, total plasma cholesterol (from 5.74 \pm 0.89 to $5.36 \pm 0.92 \mathrm{mM} ; \quad P=0.0022$ ) and plasma $\mathrm{LDL}$ cholesterol (from $3.66 \pm 0.75$ to $3.21 \pm 0.78 \mathrm{mM}$; $P=0.0001$ ) decreased significantly in patients without lipid-lowering therapy as well. There were no significant correlations between p-adiponectin and BMI (first study $r=0.054, P=0.672$; follow-up study $r=0.015, P=0.938$ ) or s-AGE. At follow up, p-adiponectin correlated significantly and inversely with fasting plasma C-peptide $\left(r_{\mathrm{s}}=-0.273 ; P=0.045\right)$, plasma $C$-peptide 6 min after a glucagon injection $\left(r_{\mathrm{s}}=-0.365 ; P=0.008 ;\right.$ Fig. 1 , top panel $)$ and LDL/HDL ratio $\left(r_{\mathrm{s}}=-0.362 ; P=0.011\right)$, and directly with plasma HDL cholesterol $\left(r_{\mathrm{s}}=0.381 ; P=0.005\right.$, Table 2).
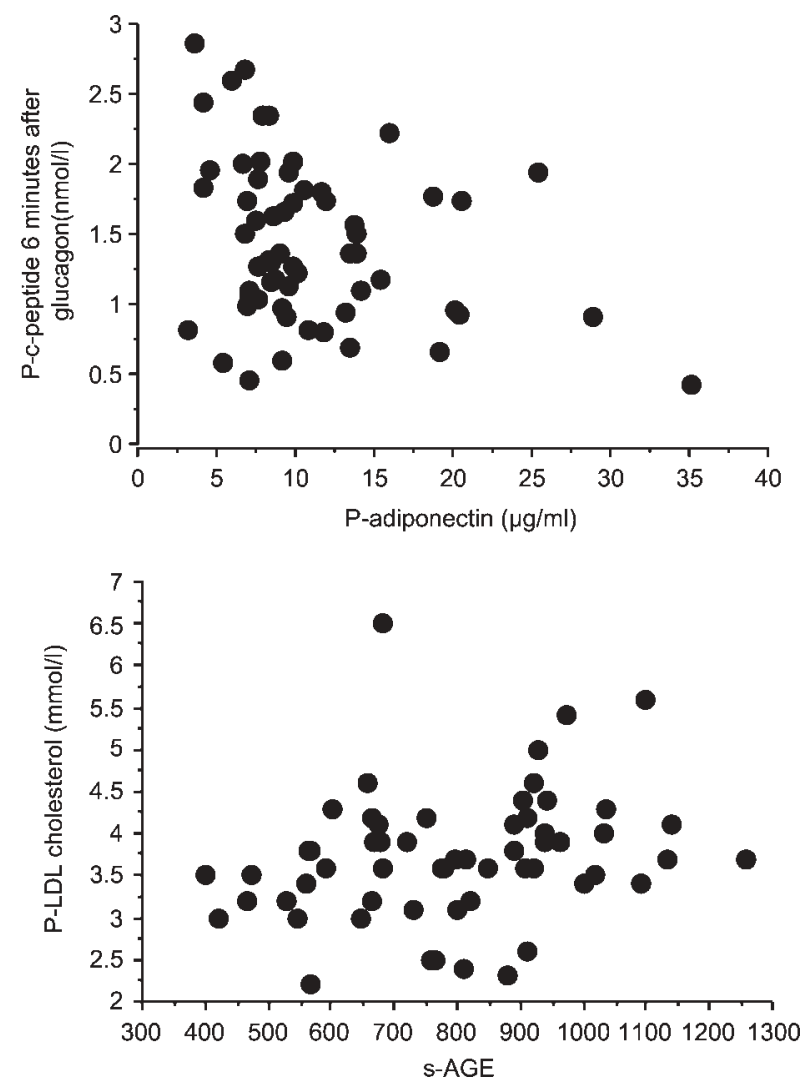

Figure 1 Top panel: correlation between plasma $(P) C$-peptide 6 min after glucagon injection versus $p$-adiponectin at follow up $\left(r_{\mathrm{s}}=-0.365 ; P=0.008\right)$ in 61 type 2 diabetic patients. Bottom panel: correlation between plasma LDL cholesterol at baseline versus $\mathrm{S}-\mathrm{AGE}$ at follow up $\left(r_{\mathrm{s}}=0.335 ; P=0.02\right)$ in 61 type 2 diabetic patients.
Table 2 Spearman's correlation coefficients between p-adiponectin concentration and BPs and metabolic variables at baseline and at follow up 3 years later in 61 type 2 diabetic patients. Significant correlations are shown in bold. P, plasma.

\begin{tabular}{lcc}
\hline & $\boldsymbol{r}$ value & $\boldsymbol{P}$ value \\
\hline Baseline & & \\
Age & 0.117 & 0.385 \\
BMl & 0.054 & 0.672 \\
Systolic/diastolic BP & $0.058 /-\mathbf{0 . 3 1 6}$ & $0.621 / 0.022$ \\
Fasting p-C-peptide & -0.237 & 0.661 \\
HbA1c & 0.017 & 0.891 \\
P-cholesterol & 0.191 & 0.138 \\
P-HDL cholesterol & 0.241 & 0.064 \\
P-LDL cholesterol & 0.077 & 0.564 \\
P-triglycerides & 0.008 & 0.952 \\
s-AGE & 0.254 & 0.067 \\
Follow up & & \\
Age & 0.003 & 0.981 \\
BMI & 0.090 & 0.493 \\
Systolic/diastolic BP & $0.075 / 0.008$ & $0.591 / 0.954$ \\
Fasting p-C-peptide & $-\mathbf{0 . 2 7 3}$ & $\mathbf{0 . 0 4 4 6}$ \\
HbA1c & -0.102 & 0.450 \\
P-cholesterol & 0.043 & 0.751 \\
P-HDL cholesterol & $\mathbf{0 . 3 8 1}$ & $\mathbf{0 . 0 0 5}$ \\
P-LDL cholesterol & -0.168 & 0.235 \\
P-triglycerides & -0.119 & 0.381 \\
s-AGE & -0.037 & 0.788 \\
\hline
\end{tabular}

\section{S-AGE}

There was a significant $(P<0.0001)$ increase in mean s-AGE from $637 \pm 242 \mathrm{ng} / \mathrm{ml}$ at baseline to $781 \pm 173 \mathrm{ng} / \mathrm{ml}$ at follow up. s-AGE correlated significantly with plasma cholesterol, both at baseline and at follow up ( $r_{\mathrm{s}}=0.283 ; P=0.041$ on both occasions), plasma HDL cholesterol at baseline $\left(r_{\mathrm{s}}=0.287\right.$; $P=0.041)$ and with plasma LDL cholesterol at follow up $\left(r_{\mathrm{s}}=0.309 ; P=0.032\right)$ (Table 3$)$. In addition, plasma LDL cholesterol at baseline correlated with sAGE at follow up $\left(r_{\mathrm{s}}=0.335 ; P=0.02\right.$; Fig. 1 , bottom panel). However, there were no significant correlations between $\mathrm{HbA1c}$ and s-AGE.

Analysis of variance (repeated design) with p-adiponectin and s-AGE as dependent variables and BMI, diastolic BP, fasting plasma C-peptide, plasma HDL and plasma LDL cholesterol showed that the increase in s-AGE was independent of the changes in covariates $(P=0.001)$, whereas the increase in p-adiponectin was totally dependent on the changes in covariates $(P=0.862)$. Accordingly, the increment in s-AGE at follow up was unrelated to lipid status.

\section{Retinopathy}

At baseline, six patients (10\%) showed diabetic retinopathy, whereas the prevalence had significantly $(P=0.0197)$ increased to $14(23 \%)$ at follow up. There was a slight but significant correlation between s-AGE at baseline and the severity of retinopathy at follow up $(r=0.281 ; P=0.0499)$. Concentrations 
Table 3 Spearman's correlation coefficients between s-AGE concentrations and BPs and metabolic variables at baseline and at follow up 3 years later in 61 type 2 diabetic patients.

\begin{tabular}{lcc}
\hline & $\boldsymbol{r}$ value & $\boldsymbol{P}$ value \\
\hline Baseline & & \\
Age & -0.022 & 0.890 \\
BMl & $-\mathbf{0 . 4 1 2}$ & $\mathbf{0 . 0 0 3}$ \\
Systolic/diastolic BP & $0.022 /-0.134$ & $0.845 / 0.491$ \\
Fasting p-C-peptide & $-\mathbf{0 . 3 1 6}$ & $\mathbf{0 . 0 2 3}$ \\
HbA1c & -0.114 & 0.414 \\
P-cholesterol & $\mathbf{0 . 2 8 3}$ & $\mathbf{0 . 0 4 1}$ \\
P-HDL cholesterol & $\mathbf{0 . 2 8 7}$ & $\mathbf{0 . 0 4 1}$ \\
P-LDL cholesterol & 0.215 & 0.128 \\
P-triglycerides & -0.010 & 0.945 \\
Follow up & & \\
Age & -0.183 & 0.186 \\
BMl & 0.030 & 0.832 \\
Systolic/diastolic BP & $0.080 /-0.159$ & $0.570 / 0.255$ \\
Fasting p-C-peptide & -0.088 & 0.527 \\
HbA1c & -0.038 & 0.784 \\
P-cholesterol & $\mathbf{0 . 2 8 3}$ & $\mathbf{0 . 0 4 2}$ \\
P-HDL cholesterol & 0.142 & 0.305 \\
P-LDL cholesterol & $\mathbf{0 . 3 0 9}$ & $\mathbf{0 . 0 3 2}$ \\
P-triglycerides & 0.053 & 0.704 \\
\hline
\end{tabular}

Significant correlations are shown in bold. P, plasma.

of p-adiponectin or s-AGE did not differ significantly between patients with and without retinopathy.

\section{Discussion}

This study showed that glycaemic control as reflected by a decrement in $\mathrm{HbA} 1 \mathrm{c}$ and dyslipidaemia as reflected by decrements in total plasma cholesterol, plasma LDL cholesterol and plasma triglycerides and increments in plasma HDL cholesterol concentrations had improved at follow up. In parallel with this improvement, p-adiponectin concentration had increased and plasma C-peptide concentrations decreased, indicating that insulin sensitivity had improved. On the other hand, s-AGE, the putative long-term consequences of hyperglycaemia, had increased at follow up.

That the increment in p-adiponectin concentration at follow up was associated with signs of increased insulin sensitivity is in line with the inverse correlation between p-adiponectin concentrations and features of the insulin-resistance syndrome observed in cross-sectional studies $(2-5)$. The previously reported $(3-5,23)$ association between high p-adiponectin and high plasma HDL cholesterol, an established anti-atherogenic factor, was also found at follow up. It has to be remembered, however, that a decrease in plasma C-peptide might not only be explained by improved insulin sensitivity, perhaps related to the increase in biguanide treatment, but might also reflect progressively decreasing $\beta$-cell function with increasing diabetes duration.

The increment of p-adiponectin and improvement in the lipid profile at follow up was not only due to the institution of pharmacological lipid lowering, as this was also seen in patients without such treatment. Hence, diet and other non-pharmacological intervention had contributed to the improvement in metabolic control as inferred from the decrease in BMI at follow up. Whether the increased p-adiponectin concentration should be considered secondary to improvement in the metabolic syndrome or whether adiponectin has a primary role in this context cannot be concluded from the current study. Although our extended statistical analysis showed that all changes observed in p-adiponectin were related to changes in its covariates, only a randomized study has the utility to clarify whether adiponectin, by decreasing intramyocellular lipid accumulation (24) and hepatic fat content (25), decreases insulin resistance $(26,27)$.

s-AGE and not only adiponectin concentrations had increased at follow up. When we related the increment in s-AGE to lipid status we found a positive correlation between plasma LDL cholesterol and s-AGE at follow up. Indeed, plasma LDL at baseline correlated with s-AGE at follow up, suggesting that elevated plasma LDL concentrations may predict future elevations in s-AGE. However, further statistical analysis demonstrated that alterations in s-AGE were unrelated to lipids. Hence, the proven increase in s-AGE seemed to be a consequence of an increasing accumulation of AGE during the observation period rather than being a consequence of dyslipidaemia. In this context, it may be appropriate to consider the fact that the patients did not obtain normoglycaemia. Hence, it might be that only slight degrees of hyperglycaemia lead to accumulation of AGE.

Our finding of increments in s-AGE may be considered logical. However, others have recently reported a lack of correlation between s-AGE concentrations and the duration of diabetes in type 1 diabetic patients (13). Indeed, a decrease in s-AGE believed to be secondary to improvement in metabolic control was reported recently (18). In contrast, we found an increase in s-AGE at follow up despite improvement in the glycaemic control, as demonstrated clearly by the decrement in $\mathrm{HbA1c}$ at follow up. The discrepancy could be related to the fact that we prospectively followed patients with type 2 and not type 1 diabetes. However, as s-AGE concentrations were not lower in type 1 diabetic patients with long duration compared with those with short duration (13), the finding of a decrease in s-AGE when the duration of type 1 diabetes increases (18) has to be confirmed in new prospective studies of type 1 diabetic patients.

Although our extended statistical analysis showed that s-AGE concentrations were independent from lipid status, it is still possible that glycation of lipids contributes to the unfavourable lipid profile in diabetes (10-12). Indeed, tissue AGE correlates with concentrations of plasma AGE-modified LDL cholesterol (28).

In our prospective study, the prevalence of retinopathy doubled over 3 years. Noteworthy is that we found 
a correlation between high s-AGE at baseline and the degree of retinopathy at follow up. Hence, our study indicates that s-AGE concentrations are important for the progression of retinopathy (15). Indeed, AGE have been reported to be elevated in serum (15) and to accumulate in the retina in diabetic retinopathy (29). AGE may have an important role in the development and progression of retinopathy.

In conclusion, concentrations of p-adiponectin and s-AGE increased over 3 years in type 2 diabetic patients. The increment in p-adiponectin was associated with improved metabolic control and reduced insulin resistance, whereas the increment in s-AGE was independent of changes in other metabolic variables.

\section{Acknowledgements}

We thank Mrs Ulrika Gustavsson and Ann Radelius for skilful technical assistance. Dr Rosmarie KientschEngel, Roche Diagnostic GmbH, Petzburg, Germany, is thanked for providing us with the CML ELISA. We also thank Jan-Åke Nilsson, BA, University of Lund, Department of Statistics and Information Processing, Malmö University Hospital, for expert statistical advice. This study was supported by grants from the Swedish Diabetes Associations, the Ernhold Lundström Foundation, Research Funds of Malmö University Hospital, Swedish Heart-Lung Foundation, Research Funds at University Hospital MAS, the Albert Påhlsson Foundation, Hulda Ahlmroth Foundation, NW Lundblad Foundation and the Swedish Life Assurances Fund.

\section{References}

1 Maeda K, Okubo K, Shimomura I, Funahashi T, Matsuzawa Y \& Matsubara K. cDNA cloning and expression of a novel adipose specific collagen-like factor, apM1 (AdiPose Most abundant Gene transcript 1). Biochemical and Biophysical Research Communications $1996221286-289$.

2 Maeda N, Shimomura I, Kishida K, Nishizawa H, Matsuda M, Nagaretani $\mathrm{H}$ et al. Diet-induced insulin resistance in mice lacking adiponectin/ACRP30. Nature Medicine 20028 731-737.

3 Shand BI, Scott RS, Elder PA \& George PM. Plasma adiponectin in overweight, nondiabetic individuals with or without insulin resistance. Diabetes Obesity \& Metabolism 20035 349-353.

4 Cnop M, Havel PJ, Utzscneider KM, Carr DB, Sinha MK, Boyko E et al. Relationship of adiponectin to body fat distribution, insulin sensitivity and plasma lipoproteins: evidence for independent roles of age and sex. Diabetologia $2003 \mathbf{4 6} 459-469$.

5 Matsubara M, Maruoka S \& Katayose S. Decreased plasma adiponectin concentrations in women with dyslipidemia. Journal of Clinical Endocrinology and Metabolism 200287 2764-2769.

6 Tschritter O, Fritsche A, Thamer C, Haap M, Shirkavand F, Rahe S et al. Plasma adiponectin concentrations predict insulin sensitivity of both glucose and lipid metabolism. Diabetes $2003 \mathbf{5 2}$ 239-243.

7 Hotta K, Funahashi T, Arita Y, Takahashi M, Matsuda M, Okamoto $\mathrm{Y}$ et al. Plasma concentrations of a novel, adiposespecific protein, adiponectin, in type 2 diabetic patients. Arteriosclerosis, Thrombosis, and Vascular Biology $2000 \quad 20$ 1595-1599.
8 Zietz B, Herfarth H, Paul G, Ehling A, Müller-Ladner U, Schölmerich J \& Schäffler A. Adiponectin represents an independent cardiovascular risk factor predicting serum HDLcholesterol levels in type 2 diabetes. FEBS Letters $2003 \mathbf{5 4 5}$ 103-104.

9 Sharp PS, Rainbow S \& Mukherjee S. Serum levels of low molecular weight advanced glycation end products in diabetic subjects. Diabetic Medicine 200320 575-579.

10 Bucala R, Makita Z, Vega G, Grundy S, Koschinsky T, Cerami A \& Vlassara H. Modification of low density lipoprotein by advanced glycation end products contributes to the dyslipidemia of diabetes and renal insufficiency. PNAS $1994919441-9445$.

11 Hedrick CC, Thorpe SR, Fu M-X, Harper CM, Yoo J, Kim S-M et al. Glycation impairs high-density lipoprotein function. Diabetologia 200043 312-320.

12 Oghami N, Nagay R, Miayazaki A, Ikemoto M, Arai H, Horiuci S \& Nakayama H. Scavenger receptor class B type I-mediated reverse cholesterol transport is inhibited by advanced glycation end products. Journal of Biological Chemistry $2001 \quad \mathbf{2 7 6}$ $13348-13355$.

13 Galler A, Muller G, Schinzel R, Kratzsch J, Kiess W \& Munch G. Impact of metabolic control and serum lipids on the concentration of advanced glycation end products in the serum of children and adolescents with type 1 diabetes, as determined by fluorescence spectroscopy and nepsilon-(carboxymethyl) lysine ELISA. Diabetes Care 200326 2609-2615.

14 Tan KC, Cwow WS, Ai VH, Metz C, Bucala R \& Lam KS. Advanced glycation end products and endothelial dysfunction in type 2 diabetes. Diabetes Care 200225 1055-1059.

15 Swamy-Mruthinti S, Miriam KC, Kumar SK, Biswas J, Ramakrishnan S, Nagaraj RH \& Sulochana KN. Immunolocalization and quantification of advanced glycation end products in retinal neovascular membranes and serum: a possible role in ocular neovascularization. Current Eye Research 200225 139-145.

16 Miura J, Yamagishi S, Uchigata Y, Takeuchi M, Yamamoto H, Makita Z \& Iwamoto Y. Serum levels of non-carboxymethyllysine advanced glycation endproducts are correlated to severity of microvascular complications in patients with type 1 diabetes. Journal of Diabetes Complications 200317 16-21.

17 Berg TJ, Dahl-Jorgensen K, Torjensen PA \& Hanssen KF. Increased serum concentrations of advanced glycated end-products (AGE) in children and adolescents with IDDM. Diabetes Care 199720 1006-1008.

18 Schiel R, Franke S, Appel T, Voigt U, Ross IS, Kientsch-Engel R et al. Improvement in quality of diabetes control and concentrations of AGE-products in patients with type 1 and insulin-treated type 2 diabetes mellitus studied over a period of 10 years (JEVIN). Journal of Diabetes Complications 200317 90-97.

19 Wroblewski M, Gottsäter A, Lindgärde F, Fernlund P \& Sundkvist G. Gender, autoantibodies, and obesity in newly diagnosed diabetic patients aged 40-75 years. Diabetes Care 1998 $21250-255$.

20 Szelag B, Wroblewski M, Castenfors J, Henricsson M, Fernlund P, Berntorp K \& Sundkvist G. Obesity, microalbuminuria, hyperinsulinaemia, and increased plasminogen activator inhibitor 1 activity associated with parasympathetic neuropathy in type 2 diabetes. Diabetes Care 199922 1907-1908.

21 Klein R, Klein BEK, Magli YL, Brothers RJ, Meuer SM \& Davis MD. An alternative method of grading diabetic retinopathy. Opthalmology $1986931183-1187$.

22 Klein R, Klein BEK, Moss SE, Davis MD \& DeMets DL. The Wisconsin epidemiologic study of diabetic retinopathy IX: four-year incidence and progression of diabetic retinopathy when age at diagnosis is less than 30 years. Archives of Ophthalmology 1989 $107237-243$.

23 Fernández-Real JM, Botas-Cervero P, López-Bermano A, Casamitjana R, Funahashi T, Delgado E et al. Adiponectin is independently associated with glycosylated haemoglobin. European Journal of Endocrinology $2004150201-205$. 
24 Weiss R, Dufour S, Groszmann A, Petersen K, Dziura J, Taksali SE et al. Low adiponectin levels in adolescent obesity: A marker of increased intramyocellular lipid accumulation. Journal of Clinical Endocrinology and Metabolism $2003 \mathbf{8 8} 2014-2018$.

25 Bajaj M, Suraamornkul S, Piper P, Hardies LJ, Glass L, Cersosimo E et al. Decreased plasma adiponectin concentrations are closely related to hepatic fat content and hepatic insulin resistance in pioglitazone-treated type 2 diabetic patients. Journal of Clinical Endocrinology and Metabolism 200489 200-206.

26 Bacha F, Gungor N, Saad R \& Arslanian SA. Adiponectin in youth. Relationship to visceral adiposity, insulin sensitivity, and $\beta$-cell function. Diabetes Care 200427 547-552.

27 Tsunekawa T, Fukatsu A, Hayashi T, Nomura N, Suzuki Y, Miyazaki A et al. Plasma adiponectin plays an important role in improving insulin resistance with glimepiride in elderly type 2 diabetic subjects. Diabetes Care 200326 285-289.

28 Stitt AW, He C, Friedman S, Scher L, Rossi P, Ong L et al. Elevated AGE-modified ApoB in sera of euglycemic, normolipidemic patients with atherosclerosis: relationship to tissue AGEs. Molecular Medicine 19973 617-627.

29 Hammes HP, Alt A, Niwa T, Clausen JT, Bretzel RG, Brownlee M \& Schleicher ED. Differential accumulation of advanced glycation end products in the course of diabetic retinopathy. Diabetologia $199942728-736$

Received 18 March 2004

Accepted 16 June 2004 